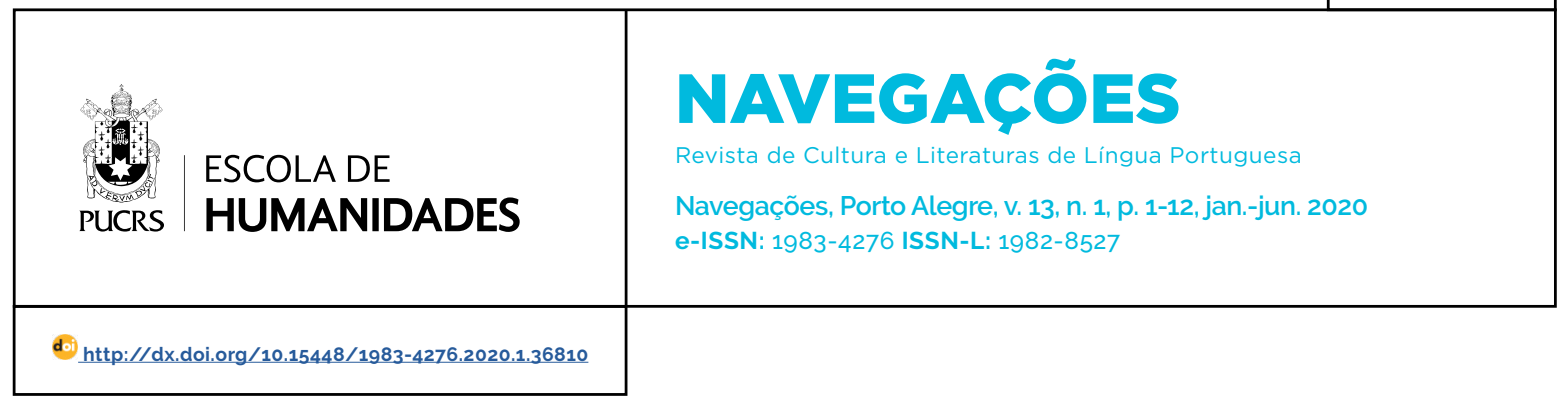

SEÇÃO: ENSAIOS

\title{
Terra e Resistência na poesia de Alda Espírito Santo ${ }^{1}$
}

\author{
Earth and Resistance in the poetry of Alda Espirito Santo
}

\section{Paulo Sergio \\ Gonçalves ${ }^{1}$ \\ orcid.org/0000-0002-5949-5170 \\ profpaulosg@gmail.com}

Recebido em: 23 jan. 2020

Aprovado em: 8 abr. 2020.

Publicado em: 10 ago. 2020.

\section{(c) (i)}

Artigo está licenciado sob forma de uma licença Creative Commons Atribuição 4.0 Internacional.
Resumo: Por meio da análise de alguns poemas de Alda Espírito Santo, o trabatho procura elucidar os pontos em que ela convoca e alerta o africano para uma resistência diante das situações opressoras impostas pelo regime colonialista. A poetisa, além de ter integrado a Casa dos Estudantes do Império, teve uma participação eficaz e decisiva no andamento das negociações da libertação do arquipélago de São Tomé e Príncipe. Ela mantém, em seus poemas, um compromisso histórico, fazendo, assim, com que seus leitores tenham consciência política e social. Por meio do sujeito poético e a partir da memória que seus poemas incitam, Alda Espírito Santo pontua e se coloca ao par de seu povo e convoca o africano de todo o continente e o negro da diáspora, despertando o Pan-africanismo e desconstruindo a imagem do colonizador. O trabalho busca, também, mostrar a representação da terra como pertença e sua valorização no imaginário africano.

Palavras-chave: Memória. Terra. Resistência.

Abstract: Through the analysis of some poems by Alda Espirito Santo, the work seeks to elucidate the points in which she summons and alerts the African to a resistance in the face of oppressive situations imposed by the colonialist regime. The poet, in addition to being part of the House of Students of the Empire, had an effective and decisive participation in the progress of the negotiations for the liberation of the archipelago of São Tomé and Principe. She maintains, in her poems, a historic commitment, thus making her readers have political and social awareness. Through the poetic subject and from the memory that his poems incite, Alda Espírito Santo scores and places himself alongside his people and summons the African from across the continent and the black from the diaspora, awakening Pan-Africanism and deconstructing the image of the colonizer. The work also seeks to show the representation of the land as belonging and its valorization in the African imagination. Keywords: Memory. Earth. Resistance.

\section{Introdução}

O arquipélago de São Tomé e Príncipe, situado no Golfo da Guiné, é considerado um dos menores países do mundo. Composto por uma população oriunda de uma miscigenação entre povos africanos continentais e portugueses colonizadores, o arquipélago assume características específicas em sua formação social e cultural.

Assim como Cabo Verde, São Tomé e Principe sofreu um tipo de colonização diferente das outras regiões do continente africano onde os portugueses estabeleceram seu aparato colonial. No arquipélago em questão, em 1470, Pêro Escobar e João de Santarém, no dia 21 de dezembro, desembarcaram nas terras santomenses e notaram que as ilhas

1 Este artigo é parte integrante da Dissertação de Mestrado de título A literatura santomense e a resistência feminina por Alda Espírito Santo e Conceição Lima, apresentada como parte da avaliação para obtenção do grau de Mestre no programa de Pós-graduação em Letras do Instituto de Letras da Universidade Federal do Rio Grande do Sul em 13 de Agosto de 2018, sob orientação da Prof. ${ }^{\text {a }}$ Dr. ${ }^{a}$ Jane Fraga Tutikian.

2 Universidade Federal do Rio Grande do Sul (UFRGS), Porto Alegre, RS, Brasil. 
eram desabitadas, o problema da falta de pessoas a serem "civilizadas" pelos então "desbravadores portugueses" tinha de ser resolvido para que o aproveitamento do arquipélago fosse satisfatório. Foi só em 1493, sob o comando de Álvaro de Caminha, que as ilhas começaram a ser povoadas, primeiramente com portugueses degredados e crianças judias, e, em seguida, com mulheres negras africanas vindas na condição de escravas e que tinham a função de procriar, ficando aos cuidados e a mercê dos homens brancos (MATA, 1998, p. 44). Com essa atitude, a intenção da coroa portuguesa era povoar as ilhas e garantir a expansão e o domínio do império português.

É baseado nesse início que o arquipélago de São Tomé e Príncipe se desenvolveu e se tornou, mais tarde, o país que hoje é, sendo assim é baseado em uma história de incertezas que o povo santomense originou-se. Incertezas quando observamos a miscigenação forçada que deixa com que o povo do arquipélago não saiba certamente de quem descende quando se fala das negras que vieram escravizadas para servir de procriadoras para a formação de um povo. Curioso e importante ressaltar que os primeiros negros africanos a pisar em solo santomense foram as mulheres, e mais adiante observa-se que a força poética feminina se torna decisiva e importante para que o país conseguisse se livrar das garras do poder colonial português.

É nesse contexto que surge a poetisa Alda Neves da Graça Espírito Santo, nascida na cidade de São Tomé, em 30 de abril de 1926, em uma família da elite dos filhos da terra. Completou seus estudos primários em São Tomé, mas passou suajuventude em Portugal, onde foi diplomada na Escola de Magistério Primário em Vila Nova de Gaia.

Em Portugal conheceu nomes importantes para a independência das então colônias africanas de língua portuguesa, tais como Amílcar Cabral, Vasco Cabral, Maria Helena Vilhena Rodrigues (esposa de Amilcar), Mário Pinto de Andrade, Agostinho Neto, António Pimentel Domingues, Francisco José
Tenreiro, Guilherme do Espírito Santo, Noémia de Souza e Marcelino dos Santos, entre outros. Eles se reuniam no tutelar "37" da rua Actor Vale, em Lisboa, local que serviu para germinação de ideias que originaram o Centro de Estudos Africanos (CEA). Foi exatamento em 1946 que Alda Espírito Santo conhece Amilcar Cabral, o grande lider africano guineense, mas que agiu, em sua vida política, como um ativista pan-africano 3 .

Alda Espírito Santo iniciou muito cedo o ofício da escrita, mas foi no ano de 1946 que sua poesia se tornou conhecida por meio de uma reunião organizada na residência de Luís Espírito Santo, onde se encontravam amigos e familiares, entre eles, Amílcar Cabral, António Pimentel Domingues e Julieta do Espírito Santo. Ema Sena Mendes, cabo-verdiana e estudante de Letras, lia poemas de cunho "subversivo" e, segundo Inocência Mata, seria numa dessas reuniões que alguns dos primeiros passos de Alda Espírito Santo teriam nascido, pois ali começaram a ser lidos os seus poemas. (MATA, 2006, p. 11-12).

Observando Jane Tutikian (2012, p. 80) quando ela afirma que existem poetas que lutam com as palavras e as aprisionam tentando entender o mundo e existem poetas que libertam as palavras para que o mundo em liberdade se entenda, podemos partir para uma reflexão importante acerca da constante luta com as letras travada pelos poetas. Alda Espírito Santo está enquadrada dentro dessa reflexão justamente entre os poetas que lutam e libertam suas palavras para que o mundo consiga se autoentender. A característica da poesia de Alda Espírito Santo nos deixa claro e evidente que seu maior objetivo era e é justamente trazer a compreensão de si mesmo para o homem e para a mulher africana.

Laura Padilha (2006, p. 22) afirma que Alda Espírito Santo assume seu papel na literatura santomense como uma mulher que escolheu a poesia para fazer dela um veículo onde pudesse caminhar pela história. Afirma ainda que a poetisa santomense buscava arrancar, do fundo do silêncio

3 O termo pan-africano vem do pan-africanismo, movimento filosófico, político e social que visava defender e resgatar os valores do negro. Em São Tomé e Príncipe. Francisco José Tenreiro foi um dos principais seguidores do Pan-africanismo, ao assumir em suas obras um forte declínio para as práticas advindas do Movimento Negritude, que, por sua vez, tinha o Pan-africanismo como um de seus motes. 
histórico de seu tempo, o alimento vindo das palavras. Dessa forma, Padilha (2006) complementa a citação de Tutikian (2012) usada acima, porque, enfim, Espírito Santo, ao lutar com as palavras e promover a libertação das mesmas, alimenta a consciência coletiva do povo santomense e do povo africano, partindo da representação feminina como chamamento e convocação ao homem africano para que se posicione diante da sua situação de colonizado. Para Alda Espírito Santo, a consciência era o passo preliminar de uma ação que poderia reverter o quadro que o africano vivia, por isso ela convoca, chama o africano 4 ao reconhecimento da necessidade de seu posicionamento diante do aparelho colonial.

Ao longo da vida, o poeta vai armazenando saberes, conhecimentos e experiências que, somados ao seu olhar poético, carregado de sensibilidade, fazem com que ele, o poeta, seja o tradutor da fala do outro:

O Poeta, que se vai naturalmente estrurando ao longo da vida, tendo em conta as suas vivências, os percursos na senda do conhecimento, já nasce com um certo daimon 5 que o predestina para, a par do seu sentir, saber imaginar, entender, interiorizar e extravasar o sentir dos outros, tornando-o universal. Ou seja, o poeta possui o dom singular de ser a memória mais profunda do tempo e da existência de cada ser humano (NEVES, 2008, p. 220).

Sendo assim, vemos em Alda Espírito Santo a preocupação pela situação do africano e uma constante luta contra a dominação colonial, que visava apenas a exploração e a opressão. Essa foi a razão que impulsionou a criação dos poemas de denúncia da poetisa santomense em seu livro É Nosso o Solo Sagrado da Terra - Poesia de protesto e luta (1978), uma coletânea de cinquenta e cinco poemas, subdivididos em temas. $\mathrm{Na}$ obra podemos observar poemas que elucidam as intenções reivindicatórias e convocativas de Espírito Santo, no sentido, mais uma vez salientamos, de levar o santomense a ocupar o seu lugar diante das barbáries que vinham assolando suas estruturas sociais e familiares ao longo da história do arquipélago desde o descobrimento e a povoação de São Tomé e Príncipe. Prova disso foi o caso da Primeira e da Segunda Colonização e também o caso do Massacre de Batepá. ${ }^{6}$ As reinvidicações de Espírito Santo se dão no sentido de situar e conscientizar o morador das ilhas de São Tomé e Príncipe em sua terra, pertença e símbolo da vida e da casa.

\section{A poesia de Alda Espírito Santo}

Vinda de raizes literárias baseadas principalmente na produção poética (durante muito tempo a literatura santomense foi vista apenas como poesia santomense) ao analisarmos a poesia de Alda Espírito Santo não podemos deixar de relembrar o primeiro poeta do arquipélago que, por meio de sua obra literária, demonstrou reconhecer-se como negro, embora seu reconhecimento tenha sido de uma forma vitimizada e inferiorizada. O poeta em questão é Caetano Costa Alegre (1864-1890):

[...] Preso ao momento histórico, não
conseguiu criar uma nova visão do ne-
gro, mas evidenciou o desejo de ques-
tionamento dessa inferioridade, estabe-
lecida pelo sistema colonial português,
produzindo uma poesia extremamente
significativa daquilo que o crítico cha-
mou de uma poética autojustificadora
do negro numa sociedade que o repelia
(SALGADO, 2010, p. 199).

Evidentemente, Costa Alegre (1864-1890), preso às limitações impostas pela sociedade lisboeta, não pode, em sua breve vida, expressar uma nova visão do negro, mas como afirma Maria Teresa Salgado (SALGADO, 2010, p. 199), o poeta deu o primeiro passo para o início de certos questionamentos face ao tratamento recebido pelo negro em Portugal e em suas colônias. Ainda sobre Costa Alegre, Alfredo Margarido nos diz:

\footnotetext{
4 Quando citamos que Alda Espírito Santo, por meio de seu sujeito poético, "chama o africano", entendemos que por meio do posicionamento pan-africano da poetisa é que ela se dirige ao negro de todo o continente e da diáspora. Essa condição é nítida em sua obra em vários poemas em que ela cita personalidades negras de outras nacionalidades.

5 Espirito.

6 Massacre ocorrido em fevereiro de 1953 onde vários santomenses foram assassinados pelas tropas do comandante Gorgulho. Teria sido esse o marco do nascimento do nacionalismo em São Tomé e Príncipe.
} 
[...] na verdade, Caetano Costa Alegre é o primeiro poeta são-tomense, e um dos primeiros poetas africanos exprimindo-se em lingua portuguesa, a tomar conhecimento da sua cor. Ou antes, das limitações que lhes eram impostas por via da sua cor, por uma sociedade preconceituosa, que ainda não conseguira esquecer que, ainda há poucos anos, o negro era apenas o escravo, admitido no ambiente doméstico, decerto, mas não autorizado a frequentar uma Universidade, a dizer em versos os seus galanteios às meninas prendadas da corte, puros raios de branco luar e, por isso, intangiveis. Não absolutamente intangiveis, entenda-se, mas completamente fora do alcance do desejo de um negro. Mas não só isso, pois que Costa Alegre encontra, na sua convivência quotidiana, no seu simples percurso através da cidade, uma série de preconceitos que pretendem impedi-lo de se assumir como consciência (MARGARIDO, 1980, p. 519-520).

Embora Caetano Costa Alegre tivesse ideais de liberdade em alguns de seus poemas, Margarido (1980, p. 523) diz que o poeta não conseguiu ultrapassar as barreiras, pois a condição na qual ele vivia, impediu que seus versos atingissem objetivos mais consistentes a ponto de reavivar o sentimento libertário necessário para um possivel levante contra as situações degradantes. A condição de segundo plano a que o negro era submetido e a posição de inferioridade, sempre ocupando funções submissas, não deixaram que Costa Alegre (1864-1890) tomasse consciência da total alienação em que vivia (MARGARIDO, 1980, p. 527).

Em seguida vemos Francisco José Tenreiro (1921-1963), cinquenta e três anos depois do último poema de Costa Alegre, exatamente no ano de 1942, representando o negro em uma radical alteração dos dados do problema (MARGARIDO, 1980, p. 527). Tenreiro, por sua vez, apresenta-se na coleção "Novo Cancioneiro" com o volume de título Ilha de Nome Santo, com poemas inseridos na linha do Movimento Negritude, trazendo uma voz de afirmação cultural e de valorização do santomense e do negro africano:

Se Costa Alegre viveu sua breve vida sob o signo do declínio da monarquia e escreveu no meio da ascendência do liberalismo republicano, quase 50 anos depois dele, na década de 1940, no auge do salazarismo, Francisco José Tenreiro vai-se revelar como uma voz de afirmação do negro e da história e da cultura de São Tomé (SALGADO, 2010, p. 200).

Alfredo Margarido (1980, p. 527) afirma que Tenreiro (1921-1963) baseava-se nas perspectivas negritudinistas que desde 1935 vinham sendo propugnadas por Leopold Sedar Senghor (Senegal) e Aimé Césaire (Martinica) e que:

[...] a lição destes dois poetas, soma-se, em Tenreiro, a presença dos poetas norte-americanos, como Countee Cullen e Langston Hugues e ainda a do cubano Nicolás Guillén. É meditando na lição destes poetas que Francisco José Tenreiro pode dar início, em língua portuguesa, a um movimento poético de negritude, onde o sentido social é a primeira e fundamental coordenada.

A poesia de Tenreiro se apresenta como uma poesia de negação e de denúncia, isso traz e intensifica uma nova roupagem à poesia africana e, particularmente, à poesia santomense (MARGARIDO, 1980, p. 532).

Observando as linhas de ação dos poetas Caetano Costa Alegre e Francisco José Tenreiro, tendo o primeiro iniciado seus passos em direção ao reconhecimento da condição do negro, e o segundo tendo assumido tal posição de forma a situar-se cultural e socialmente, chegamos na poesia de Alda Espírito Santo, cujo ponto de partida coincide exatamente com o momento de afirmação e de posicionamento negritudinista das Literaturas Africanas de Língua Portuguesa. A representração da voz do negro africano permeada pelas perspectivas observadas pelo Movimento Negritude na África de língua portuguesa, apresenta uma coerência não só nos escritos de Alda Espírito Santo, mas também em outros escritores e personagens importantes de todo o cenário cultural africano.

Tem, todavia, uma coerência autoral (Alda Espirito Santo, Agostinho Neto, António Jacinto, Francisco José Tenreiro, Noémia de Souza, Viriato da Cruz) que dá corpo poético ao entendimento deste momento histórico e à "linha" de pensamento que lhe subjaz: a negritude. Coerência que é reforçada pela nota final de Francisco José Tenreiro ao reafirmar que "os pequenos Camões de pele preta, os ínfimos 
Anteros...exprimem a Negritude"7. [...] Porque a Negritude põe de lado facções politicas e patriotismo de mal de pote, e repousa numa consciência em vias de renascimento, o Negro neste diálogo que agora se inicia entre a Europa e a África, é estruturalmente claro e directo nas suas falas, amargo e duro por vezes..." (MONTEIRO, 2001, p. 124).

Percebemos, portanto, a poesia de Alda Espírito Santo como uma poesia de resistência. Para Alfredo Bosi (1996, p. 11), a resistência pode ser entendida como um "apelo à força de vontade que resiste a outra força que é exterior ao sujeito" ou seja, resistir, oferecer resistência é, justamente, opor a própria força à força alheia. Sendo assim, juntamente com o sentimento de resistência existente na poesia de Espírito Santo, observase também, a invocação do nacionalismo e do amor à terra santomense.

O colonizado sofre uma interferência cultural e psicológica quando the é introjetado o sentido de que tudo que vem do Ocidente é melhor e é correto. Somente as condições extremas de segregação a que são submetidos, aliadas ao declame ininterrupto dos intelectuais autóctones, podem despertar o sentimento de libertação de tais condições.

O árduo trabalho que a poesia santomense assume de convocar o povo africano, e no caso de Alda Espírito Santo, de convocar, em especial, a mulher africana a um posicionamento de resistência, tem como principal objetivo quebrar alguns estigmas criados pela violência que Fanon (1968, p. 32) esclarece ao falar da violência com que os valores brancos foram afirmados e a agressividade que impregnou o confronto vitorioso desses valores para com o modo de vida do colonizado. Para Frantz Fanon (1968) toda essa violência é visualizada pelo colonizado no processo de descolonização, e agora os valores brancos não mais o enganam.

Em suas poesias, Espírito Santo (1926-2010) mostra o compromisso assumido com a situação de seu povo, portanto ela desconstrói, em sua obra poética, a fala do colononizador que até então regia o imaginário do povo santomense e do povo africano de língua portuguesa. Uma caracteristica importante da ação colonialista diante do colonizado é justamente a interposição de um discurso que afirma a importância da subjetividade e da individualidade pois:

[...] O intelectual colonizado aprendera com seus mestres que o individuo deve afirmar-se. A burguesia colonialista introduzira a golpes de pilão no espírito do colonizado a ideia de uma sociedade de individuos em que cada um se encerra em sua subjetividade, em que a riqueza é a do pensamento. Ora, o colonizado que tiver a sorte de se entranhar no povo durante a luta de libertação descobrirá a falsidade dessa teoria. As formas de organização da luta logo lhe proporão um vocabulário insólito. O irmão, a irmã, o camarada são palavras proscritas pela burguesia colonialista porque, para ela, meu irmão é meu bolso [...] (FANON, 1968, p. 35).

Justamente contra esse apontamento observado por Fanon é que a poesia de Alda Espírito Santo luta. Por meio de palavras e de ritmo, a poetisa grita e convoca para a união, para as mãos dadas diante de uma situação que só pode ser vencida se houver consciência e união. Além dessa característica, Espírito Santo carrega em suas letras um inflamado teor nacionalista e a afirmação da terra quase como integrante de seu corpo.

Para que se tornem claras e evidentes as afirmações a respeito da obra da poetisa santomense, passaremos a analisar alguns de seus poemas, publicados no livro É Nosso o Solo Sagrado da Terra - Poesia de protesto e luta:

Mas, grosso modo, os poemas de É Nosso - Solo Sagrado da Terra - Poesia de Protesto e Luta são de matriz nacionalista, de denúncia da situação colonial, da repressão colonial-fascista (o massacre de Batepá). É poesia do canto às figuras que se erigem a símbolos da resistência colonial: o contratado queimando vida nas roças de cacau e de café; o contratado desenraizado (de que o poema emblemático é "Avó Mariana") - um tema também textualizado por Francisco José Tenreiro ("Romance de Sinhá Carlota") e por Conceição Lima, tanto em O Útero da Casa (2004) quando em A Dolorosa Raiz do Micondó (2006); o angolar e a 
Mulher, símbolo da Terra e da África. A própria divisão do livro obedece nitidamente a uma concepção temática que remete para uma evolução de um percurso político: "Poemas da Juventude", "Poema Mensagem", "Por entre os muros da repressão", "Aos Combatentes da Liberdade", "A Legitima Defesa", "Cela Non Vugu" (expressão do crioulo forro que literalmente significa: "temos que nos mexer!"). São ao todo cinquenta e cinco poemas, precedidos de um longo prefácio (justificativo, mais do que interpretativo) da autora. Os poemas assim agrupados denunciam uma estética que relava da concepção do labor literário como possibilidade de veículo político-ideológico (MATA, 2006, p. 16).

Nas primeiras páginas da obra acima citada, na edição publicada pela Editora Ulmeiro (1978), podemos observar o Hino de São Tomé e Príncipe que foi escrito por Alda Espírito Santo (1926-2010).

Independência total

Glorioso canto do povo

Independência total

Hino sagrado de combate

Dinamismo

Na luta nacional,

No pais soberano de S. Tomé e Príncipe ।

Guerrilheiro da guerra sem armas na mão Chama viva na alma do povo

Congregando os filhos das ilhas

Em redor da Pátria Imortal

II

Independência total, total e completa

Construindo no progresso e na paz

A nação mais ditosa da Terra

Com os braços heróicos do povo

Independência total

Glorioso canto do povo

Independência total

Hino sagrado de combate

III

Trabalhando, lutando, lutando e vencendo

Caminhamos a passos gigantes

Na cruzada dos povos africanos

Hasteando a bandeira nacional

IV
Voz do povo, presente, presente em conjunto Vibra rijo no coro da esperança

Ser herói na hora do perigo

Ser herói no ressurgir do País $\checkmark$

Independência total

Glorioso canto do povo

Independência total

Hino sagrado de combate

Dinamismo

Na luta nacional,

No pais soberano de S. Tomé e Príncipe

(ESPÍRITO SANTO, 1978, p. 6)

Declarando o combate pela liberdade, a canção nacionalista de São Tomé e Príncipe, o seu Hino Nacional, traz uma letra de exaltação aos heróis santomenses que, ao longo dos anos, caíram martirizados pelos seriados processos de opressão colonialista.

Na primeira estrofe depois do refrão do Hino Nacional de São Tomé e Príncipe, Alda Espírito Santo declara o caráter da libertação do país dizendo "Guerrilheiro da guerra sem armas na mão", relembrando que o arquipélago santomense conseguiu sua libertação sem precisar de um combate armado. Mas vale também lembrar que as vitimas ou mártires desse processo de libertação existiram mesmo não havendo um combate armado para que a libertação fosse conquistada. Vale lembrar - Massacre de Batepá no ano de 1953, massacre desencadeado pelo Governador Gorgulho, e as perseguições sofridas por conta da Primeira e da Segunda Colonização ${ }^{8}$ de São Tomé e Príncipe.

Os atos heróicos, na hora do perigo e no ressurgir do país que Espírito Santo cita no verso IV do Hino Nacional de São Tomé e Príncipe, remontam ao exercicio de resistência, um dos motes que regem sua produção literária:

O contexto determinante da presença no mundo, em luta contra o padrão colonial de exploração capitalista, feroz e ultrapassado nos seus métodos, uniu os

\footnotetext{
8 A Primeira Colonização do arquipélago de São Tomé e Príncipe se deu pela chegada dos portugueses por meio dos navegadores Pêro Escobar e João de Santarém no ano de 1470. A chamada Segunda Colonização deu-se depois do grande pousio (termo criado por Francisco José Tenreiro para referir-se ao periodo de 300 anos de enfraquecimento do plantio de cana de açúcar) onde os descendentes dos primeiros portugueses e das primeiras negras já formavam uma espécie aristocracia mestiça como proprietários de terras no arquipélago. Com o advento de São Tomé e Principe tornar-se um entreposto de escravos, a cultura do café e do cacau foi introduzida nas ithas, ocasionando a desapropriação destas terras que até ali pertenciam aos mestiços herdeiros. Novas familias brancas portuguesas vão para o arquipélago e este fato é chamado de Segunda Colonização.
} 
povos africanos dominados pela potência colonial portuguesa, numa frente de luta conjunta no eclodir das primeiras independências dos povos africanos subjugados pelas outras potências do Ocidente. Esse contexto determinou o compromisso dos povos africanos dessa região do continente, que encetaram a "Grande Marcha" liderada pelos movimentos nacionalistas de cada um desses paises, decididos a varrerem o colonialismo do solo pátrio e a abolirem duma vez para sempre a exploração do homem pelo homem [...] (ESPIRITO SANTO, 1978, p. 9).

Segundo Marx e Engels (2005, p. 40), a história de todas as sociedades existentes é sem dúvida a história da luta de classes, e em um Estado onde primeiramente a escravidão, depois a servidão e o contrato estiveram presentes em sua formação, isso não seria diferente, portanto não haveria nenhuma perspectiva de mudança desse quadro, se não houvesse um levante que, em São Tomé e Principe, se dá por meio da conscientização do povo, por diversas vezes reivindicada em versos pela poetisa.

Como um forte instrumento de afirmação identitária, os poemas existentes na obra É Nosso o Solo Sagrado Da Terra - Poesia de protesto e luta (1978) são símbolos de compromisso com a luta dos povos oprimidos e da militância africana contra cinco séculos de estagnação. Espírito Santo ainda afirma que os poemas de seu livro surgem das raizes da terra, que é identificada com o processo da luta (ESPÍRITO SANTO, 1978, p. 10).

Alda Espírito Santo assume o compromisso de, como seus próprios versos dizem, "trazer para o palco da vida/ pedaços da minha gente" (MARGARIDO, 1980, p. 539). Ela tem a consciência e o compromisso de solidificar, por meio de seus versos, aquilo que está obscuro e aquilo que as pessoas não conseguem enxergar com um simples olhar, tais como os problemas sociais e as más condições de vida trazidos pela exploração do homem pelo homem. E como afirma Fanon (1968, p. 26), "a descolonização jamais passa despercebida porque atinge o ser, modifica fundamentalmente o ser, transforma espectadores sobrecarregados de inessencialidade em alfôres privilegiados", para ele é necessário responder com a mesma violência com a qual a colonização foi imposta, mesmo em São Tomé e Principe, onde efetivamente não houve uma luta armada no momento da descolonização, mas onde outras lutas, no decorrer dos anos foram se tornando, aos poucos, o motivo da necessidade de conscientização e do nascimento do nacionalismo. Dessa forma, Padilha (2006, p. 21) concorda com Fanon quando diz que a busca pela solidaredade e pelo fim da opressão, exigem que os poetas se posicionem com violência em seus versos contra o processo de colonização.

A poetisa faz um passeio histórico e registra os passos de seu país desde de seu surgimento, por meio dos versos do poema "S. Tomé e Príncipe" (ESPÍRITO SANTO, 1978, p. 27). Na primeira estrofe, a poetisa contempla a beleza da itha e sua localização, mas já no início cita as guerras e o posicionamento resistente do santomense desde o tempo da imposição do contrato:
Milhas marinhas ao longo da costa africana
Envolvendo palmares, obós ${ }^{9}$, pães de açúcar Acidentadas ilhas do Amador Ilhas acidentadas da Guerra do Mato Terreiro da luta da resistência Três séculos, guerrilhas de escravos Resistentes da luta colonial "Estampa primeira da resistência nacional Abalando os alicerces do feudo colono O ciclo do Amador é o prelúdio da história do povo Igigante] (ESPIRITO SANTO, 1978, p. 27)

Em seguida, Alda Espírito Santo mostra o tráfico de escravos para a América do Sul e a presença dos navios negreiros na história do arquipélago, que servia de entreposto de escravos para o Brasil:

Gigante no paradoxo dimensional da terra Navios negreiros, fantasmas da rota atlântica Tubarões sugadores de negros escravos empilhados

Nos porões da morte dos donos do ocidente Engenhos de açúcar, cana sacarina

Museus diluidos na leva para o Brasil

A fonte tropical brota fértil

No cacau colono do grande capital

A África é fértil em mercado escravo (ESPÍRITO SANTO, 1978, p. 27) 
A memória que a poetisa busca serve como instrumento de conscientização do santomense, sempre a visitar seu passado para que não esqueça as origens de seu país e de seu povo e, dessa forma, com a história em punho, possa reconstruir cada vez mais forte seus argumentos de resistência.

O fator que o poema de Espírito Santo desencadeia é justamente o gatilho que aciona a memória coletiva do santomense, mesmo o mais jovem, aquele que é o resistente do "hoje", mas que não viveu o "ontem", e, por meio de suas citações poéticas, conhece a história e a origem de seu povo e de as suas raízes. São as confrontações que a memória individual traz com a memória coletiva (HALBWACHS, 1968, p. 25). Para Halbwachs nós nunca estamos sós, e os acontecimentos por nós presenciados e vividos, se tornam parte da memória coletiva quando testemunhamos a partir de nós e fazemos com que esse testemiunho sirva em comum para um determinado grupo. A memória individual, portanto, continua existindo, mas está ligada a fatores e a contextos com outras pessoas, o que faz com que aconteça uma espécie de compartilhamento da memória individual, que se torna, então,uma memória coletiva:

Mas nossas lembranças permanecem coletivas, e elas nos são lembradas pelos outros, mesmo que se trate de acontecimentos nos quais só nós estivemos envolvidos, e com objetos que só nós vimos. É porque, em realidade, nunca estamos sós [...] (HALBWACHS, 1968, p. 26).

No meio de seus versos, Espírito Santo ainda lembra a resposta que o colono deu à resistência, fazendo uma alusão ao Massacre de Batepá:

A revolta persistente faz história E nas décadas do século finda o poisio Rusgas várias são tentadas contra o forro E o forro riposta contra as rusgas Resistência Santomense te um fim Não ceder ao contrato escravo das roças de cacau E um massacre é resposta à resistência (ESPIRITO SANTO, 1978, p. 28).

Mas no fim desse poema, a poetisa enfatiza o resultado "glorioso" de todos os esforços feitos pelo povo santomense ao longo do tempo, sempre evocando a supremacia identitária e a reafirmação do santomense como ator de seu próprio destino. Ela conta, nesse poema que atravessa a história do arquipélago, a formação do movimento de libertação e a conquista da tão sonhada independência, e mais uma vez, a alusão ao solo, a pertença ao solo, a afirmação do solo como casa, o solo sagrado da terra:

\author{
O povo inteiro da pátria soberana \\ Em directa democracia. \\ Nacionaliza terras e o solo da da nação \\ Setembro 30 na História \\ É princípio soberano \\ Duma batalha económica \\ Enterrando a exploração. \\ Batalha da produção \\ Consciência da nação \\ A luta da reconstrução \\ Dura batalha, consciente, \\ É luta armada do povo \\ Contra o jogo da exploração. \\ MLSTP presente \\ Conduz a força do povo \\ Na dura, batalha dura \\ Afogando a exploração. \\ Da ponta norte Ilhéu Bombom \\ À Ponta meridional \\ Da passagem do equador \\ Amador - MLSTP \\ Vitória da Resistência \\ Do heróico povo Santomense \\ (ESPÍRITO SANTO, 1978, p. 29-30, grifo nosso).
}

O ritmo do poema é um dos recursos usados pela poetisa como objetivo de enfatizar o protesto e a luta. No fragmento acima podemos perceber a reiteração da letra "T" que assinala a percussão marcada pelo ritmo do poema. O ritmo é formado pela sucessão de unidades rítmicas resultantes da alternância entre sílabas acentuadas e não acentuadas (GOLDSTEIN, 1990, p. 11). Também são perceptiveis as palavras escritas com letra maíuscula (História, Resistência, Santomense), que se apresentam dessa forma não por acaso, mas com a mesma intenção com que todo o poema se apresenta: contar a História de Resistência do Santomense. 
A coletânea de poemas que foi publicada em É Nosso o Solo Sagrado Da Terra - Poesia de protesto e luta se apresenta obedecendo uma divisão temática antre eles, divisão essa que Inocência Mata nos explica da seguinte forma:[...] A própria divisão do livro obedece nitidamente a uma concepção temática que remete para uma evolução de um percurso politico: "Poemas da Juventude", "Poema Mensagem", "Por entre os muros da repressão", "Aos Combatentes da Liberdade", "A Legítima Defesa", "Cela Non Vugu" (expressão do crioulo forro que literalmente significa: "temos que nos mexer!"). São ao todo cinquenta e cinco poemas, precedidos de um longo prefácio (justificativo, mais do que interpretativo) da autora. Os poemas assim agrupados denunciam uma estética que relava da concepção do labor literário como possibilidade de veículo político-ideológico (MATA, 2006, p. 16).

A partir de agora iremos observar mais alguns poemas e elucidar os elementos que enfatizam os sentimentos de pertença à terra e o exercício da resistência, sendo assim, podemos observar o primeiro poema apresentado na seção intitulada "Poemas da Juventude", que recebe o título sugestivo de "Vozes das Ilhas" (ESPÍRITO SANTO, 1978, p. 33-34)

Sobre o mar das nossas terras, por sobre a Itormenta

Paira o espectro da incerteza

Nas nossas mãos erguendo-se temerosas

A espera de um gesto, duma harmonia

A pautar os nossos longos passos

Através da jornada que se avizinha dura e Isangrenta.

$\mathrm{Ai}$, longos caminhos da minha terra, longos Icaminhos da terra amada.

A angústia reside permanente nos nossos lolhos, à espera dos primeiros passos.

Nessa hora breve como aurora, rompendo por Icima das nossas cabeças

Terra amada, a tua oferenda será um longo Iholocausto dos teus filhos...

O mar dos tubarões vai rugir forte, terra amada.

Do teu ventre em brasa a semente surgirá, [Mãe terra.

Teus filhos, gerados na dor e na passividade, Isaberão por fim o seu destino

Mas até o acertar dos passos, Mãe, um rio de [loucura há-de estuar.
Praias da minha terra, grotas perdidas nos lobós ${ }^{10}$ distantes

Já ouço o canto angustiado do ossobô ${ }^{11}$ a [semear a tormenta

E o misterioso grito de conóbia ${ }^{12}$ em seus [longos agouros.

Mas o homem dos trópicos de mãos levantadas Ivai redimir a gleba ${ }^{13}$.

O canto do silêncio, um longo canto de punhos [cerrados

Será a resposta do homem aos tubarões dos Imares.

Contextualizando o poema acima podemos perceber a grande preocupação e os anseios por liberdade que brotavam na consciência da poetisa. Já nos primeiros versos do poema Espírito Santo declara a incerteza que paira sobre o arquipélago, que atravessava um tempo de transformação. O eu lírico prevê tempos de luta logo à frente e afirma que o holocausto será inevitável.

Um ponto importante neste poema, além da resistência evidente do eu lírico, é justamente a afirmação da terra como "Mãe". Essa afirmação traz novamente à tona uma constante na fala poética de Espirito Santo: a afirmação da casa, da terra como mãe. Alda Espírito Santo, por meio do eu lírico, fala das angústias e da previsão de tempos ruins à frente, porém termina o poema confirmando que permanecerão de punhos cerrados na terra-mãe.

Alda Espírito Santo está identificando a terra como mãe e reafirmando seu lugar de pertença. Gaston Bachelard diz que precisamos ter um lugar no mundo, um canto que é só nosso e onde nos enraizamos, um verdadeiro cosmos de onde nos identificamos, pois até a mais modesta habitação, vista de dentro, é bela (BACHELARD, 1993, p. 200), é dali, de dentro de seu lugar que o santomense irá reconquistar o seu espaço tomado pelo colonizador. Em seus poemas, Espirito Santo sempre traz o santomense para a sua casa, para a sua terra, para dali partirem para a luta, para a resistência, porque a casa é o lugar, "é um dos maiores poderes de integração

\footnotetext{
Floresta densa.

Pássaro dos bosques de cores garridas que anuncia as grandes chuvas

Pássaro considerado anunciador de maus presságios
}

3 Pátria. 
para os pensamentos, para as lembranças e para os sonhos do homem" (BACHELARD, 1993. p. 201), dessa forma, Espírito Santo convoca o santomense ao aconchego da casa, da terra, da mãe, pois é ali que o homem se sente seguro.

O próximo poema a ser analisado é "Para lá da Praia" (ESPÍRITO SANTO, 1978, p. 47-48):

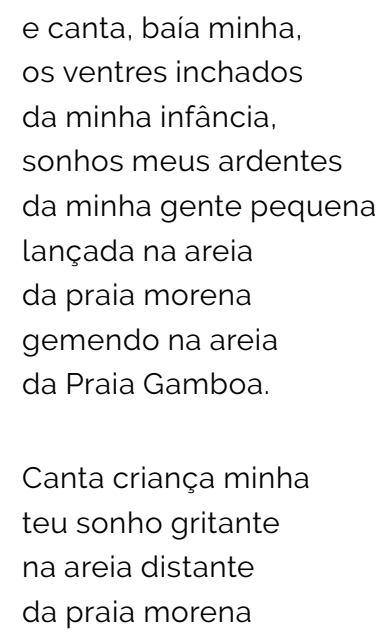

Mais uma vez, Alda Espírito Santo usa o recurso da memória para que o eu lírico teça uma construção de sentidos nos versos deste poema. A poetisa traz à tona as suas lembranças, tornando-as uma lembrança coletiva, a lembrança de uma nação:

Na luta da fome da gente pequena, a mamã africana ressalta na infância dos poetas que atravessaram os ingremes caminhos da meninice, testemunhando a dupla colonização da mamã negra jungida à canga da desintegração social [...] (ESPÍRITO SANTO, 1978, p. 178).

Conforme afirma Paul Ricoeur (2007), o vínculo original da consciência reside na memória:

[...] De um lado, as lembranças distribuem-se e se organizam em niveis de sentido, em arquipélagos, eventualmente separados por abismos, de outro, a memória continua sendo a capacidade de percorrer, de remontar no tempo, sem que nada, em principio, proiba prosseguir esse movimento sem solução de continuidade. É principalmente na narrativa que se articulam as lembranças no plural e a memória no singular, a diferenciação e a continuidade. Assim retrocedo à minha infância, com o sentimento de que as coisas se passaram numa outra época [...] (RICOEUR, 2007, p. 108).

O poema nos fala da época em que os habitantes do litoral santomense foram desapropriados de suas terras. Aqui, Alda Espírito Santo não deixa morrer a lembrança de que os angolares foram violentamente marginalizados pelo modelo colonialista que se instalava em São Tomé e Príncipe há séculos.

Observamos, também, na primeira estrofe, mais precisamente no primeiro verso do poema, que agora o eu lírico se refere à terra com o pronome possessivo "nossa". Com esse recurso, ela traz o leitor para a pertença da terra. Essa estratégia da poetisa faz com que todos os outros versos a seguir, que estão trazendo relatos de experiência vivida por ela, sejam incorporados no sentimento de pertença de todo o povo santomense. É uma espécie de estratégia que convoca o "natural da

\footnotetext{
Folha de palmeira.

Gamela onde as peixeiras transportam o peixe.

Trabalho, lida diária
} 
terra" a compartilhar dos sentimentos remotos que residem na memória individual que agora se faz coletiva, como nos explica Halbwachs:

Certamente, se nossa impressão pode apoiar-se não somente sobre nossa lembrança, mas também sobre a dos outros, nossa confiança na exatidão de nossa evocação será maior, como se uma mesma experiência fosse recomeçada, não somente pela mesma pessoa, mas por várias [...] (HALBWACHS, 1968, p. 25).

O problema da fome e da busca de saciála também foi tratado pela poetisa no poema "Angolares" (ESPIRITO SANTO, 1978, p. 49), no trecho que diz "Canoa flutuando sobre as procelas das águas/lá vai o barquinho da fome.", demonstrando assim que o único meio de subsistência a que os angolares foram submetidos, foi a pesca, a partir da segunda colonização.

\section{Considerações finais}

Espírito Santo termina seu livro de poemas com a mesma bandeira inicial, a convocação, o protesto, a resistência e a forte relação com a terra e demonstrando a influência da insularidade em sua criação poética.. No último verso o sujeito poético garante que seu povo é um povo que avança, em busca da totalidade de sua independência. Observando os apontamentos de Padilha (2006, p. 128), vemos que os possíveis novos obstáculos com certeza darão vazão para que surjam novos cantos.

Comenta Secco (2016, p. 146) que Alda Espírito Santo sempre teve um comprometimento histórico em seus poemas, o que a pesquisadora chama de "útero das ilhas", que nada mais é do que a identificação com o arquipélago. Ela ainda afirma que as gerações mais jovens devem um tributo às contribuições poéticas de Alda Espírito Santo, que conta em detalhes, em seus versos, a geração de seu país.

Perecebe-se portanto, na poesia de resistência de Alda Espírito Santo, a importância e a força da participação feminina, não só da poetisa, mas da mulher santomense, sob a voz poética de conscientização emanada da obra poética.

O legado de Alda Espírito Santo continua vivo até os dias de hoje no arquipélago santomense e está presente na poesia contemporânea de Conceição Lima, porém o mais importante é que a poesia de Espírito Santo não deixou que o povo santomense e se desviasse de seus objetivos em busca da independência de seu país. Ao lado de outras personagens históricas, a poetisa santomense convocou de seu arquipélago, considerado um dos menores paises do mundo, a mulher e o homem africano por meio do sentimnto pan-africano.

A força da mulher africana de São Tomé e Príncipe, cantada nos versos de Espírito Santo, talvez venha do fato de que os primeiros africanos que pisaram naquelas ilhas, tenham sido mulheres na condição de escravas e com o dever de procriar, miscigenar obrigatoriamente, com os portugueses ali enviados para, desta forma, constituirem um povo "natural da terra".

Alda Espírito Santo, a "Dona Alda", como carinhosamente é chamada em seu país, morreu no ano de 2010, no dia 9 de março, mas sua poesia vive e ecoa nos cantos e recantos de São Tomé e Príncipe, sempre trazendo os fatos históricos à tona, para que o jovem de São Tomé e Principe não esqueça de seus antepassados, que morreram e lutaram pela liberdade que hoje gozam.

\section{Referências}

BACHELARD, Gaston. Vida e Obra. São Paulo: Livraria Martins Fontes Editora Ltda, 1993. (Coleção Os Pensadores). Tradução de Antônio da Costa Leal e Lídia do Valle Santos Leal.

BOSI, Alfredo. Narrativa e Resistência. Revista Itinerários, Araraquara, n. 10, p.11-27, 1996.

ESPÍRITO SANTO, Alda. É Nosso o Solo Sagrado da Terra: Poesia de protesto e luta. Lisboa: Editora Ulmeiro, 1978. (Colecção Vozes das Ilhas)

FANON, Frantz. Os condenados da terra. Rio de Janeiro: Editora Civilização Brasileira S/a, 1968. (Série Política). Tradução de José Laurênio de Mello.

GOLDSTEIN, Norma. Versos, sons, ritmos. 6. ed. São Paulo: Ática, 1990. (Princípios).

HALBWACHS, Maurice. A memória coletiva. São PauLo: Editora Revista dos Tribunais Ltda, 1968. (Vértice). Tradução de Laurent Léon Schaffter.

MARGARIDO, Alfredo. Estudo sobre Literaturas das Nações Africanas de Lingua Portuguesa. Lisboa: Sociedade Industrial Gráfica Telles da Silva Ltda, 1980. (Série: A regra do jogo) 
MATA, Inocência. Diálogo com as Ilhas: Sobre Cultura e Literatura de São Tomé e Príncipe. Lisboa: Edições Colibri, 1998

Endurecer-se sem perder a ternura In: MATA, Inocência; PADILHA, Laura Cavalcante (Comp.). A Poesia e a Vida: Homenagem a Alda Espirito Santo. Lisboa: Edições Colibri, 2006. p. 11-19. Coordenação de Inocência Mata.

MARX, Karl; ENGELS, Friedrich. Manifesto Comunista. São Paulo: Boitempo Editorial, 2005. Tradução de Álvaro Pina

MONTEIRO, Maria Rosa da Rocha Valente Sil. C.E.I. Celeiro do Sonho: Geração da "Mensagem". 2001. 365 f. Tese (Doutorado) - Curso de Letras e Ciências Humanas, Instituto de Letras e Ciências Humanas da Universidade do Minho, Universidade do Minho Portugal, Braga, 2001.

NEVES, Alda. Marcas de nacionalismo na poesia de Alda Espírito Santo. Revista Comunidades Imaginadas: Nação e Nacionalismos em África, [s.l.], p.219-225, 2008. Imprensa da Universidade de Coimbra. http://dx.doi.org/10.14195/978-98926-0339-1_16. Disponivel em: <http://hdl.handle. net/10316.2/32166>. Acesso em: 23 jan. 1018.

PADILHA, Laura Cavalcante. Uma voz insubordinada e solidária. In: MATA, Inocência; PADILHA, Laura Cavalcante (Comp.). A Poesia e a Vida: Homenagem a Alda Espírito Santo. Lisboa: Edições Colibri, 2006. p. 21-27. Coordenação de Inocência Mata.

RICOUER, Paul. A memória, a história, o esquecimento. Campinas: Editora da Unicamp, 2007. Tradução de Alain François [et al.].

SALGADO, Maria Teresa. Francisco José Tenreiro: ambiguidade e ironia a favor da poesia. In: SECCO, Carmen Lucia Tindó; SALGADO, Maria Teresa; JORGE, Silvio Renato (Org.). Pensando África: Literatura, Arte, Cultura e Ensino. Rio de Janeiro: Fundação Biblioteca Nacional, 2010. p. 198-205.

TUTIKIAN, Jane. O Poema Porta Aberta Tocha Acesa de Conceição Lima. Abril: Revista do Núcleo de Estudos de Literatura Portuguesa e Africana da UFF Rio de Janeiro, v. 5, n. 9, p.79-92, 2012.

\section{Paulo Sergilo Gonçalves}

Licenciado em Letras - Português e Inglês pela SECAL/ PR; Mestre em Letras pela UFRGS/RS, doutorando em Letras pela Universidade Federal do Rio Grande do Sul (UFRGS, Porto Alegre, RS, Brasil), linha de pesquisa Pós-colonialismo e Identidades. Professor de Antropologia e Sociedade, Comunicação Contemporânea, Lingua Portuguesa e Redação Instrumental da Faculdade Estácio de Sá de Porto Alegre, RS, Brasil.

\section{Endereço para correspondência}

Paulo Sergio Gonçalves

Faculdade Estácio de Sá de Porto Alegre (FARGS)

Rua Mal. Floriano Peixoto, 626
Centro Histórico, 90020-060

Porto Alegre, RS, Brasil 